\title{
Determinants of Potentially Unnecessary Cervical Cancer Screenings in American Women
}

\author{
Munseok Seo, James R. Langabeer II \\ School of Biomedical Informatics, University of Texas Health Science Center, Houston, TX, USA
}

Objectives: To identify factors responsible for potentially clinically unnecessary cervical cancer screenings in women with prior hysterectomy.

Methods: A retrospective cross-sectional study was conducted using the Centers for Disease Control and Prevention's Behavioral Risk Factor Surveillance System (BRFSS). This study targeted adult women and examined whether they received a both a Papanicolaou (Pap) test and undergone a hysterectomy in the last three years. We conducted multivariate analyses, including weighted proportions and odds ratios (ORs), based on the modified BRFSS weighting method (raking). The inclusion criteria were adult women ( $>18$ years old) who reported having received a Pap test within the last 3 years.

Results: Of all women ( $n=252$ 391), 72366 had received a Pap test, and 32935 of those women (45\%, or 12.5 million, weighted) had a prior hysterectomy. We found that age, race/ethnicity, marital status, family income, health status, time since last routine checkup, and health insurance coverage were all significant predictors. Black, non-Hispanic women were 2.23 times more likely to receive Pap testing after a hysterectomy than white women (OR, 2.23; $95 \%$ confidence interval [Cl], 1.99 to 2.50). Similarly, the odds for Hispanic women were 2.34 times higher ( $\mathrm{OR}, 2.34 ; 95 \% \mathrm{Cl}, 1.97$ to 2.80). The odds were also higher for those who were married $(\mathrm{OR}, 1.17 ; 95 \% \mathrm{Cl}, 1.08$ to 1.27$)$, healthier ( $O R, 1.24 ; 95 \% \mathrm{Cl}, 1.14$ to 1.35$)$, and had health insurance $(\mathrm{OR}, 1.54 ; 95 \% \mathrm{Cl}, 1.28$ to 1.84$)$, after controlling for confounders.

Conclusions: We conclude that women may potentially receive Pap tests even if they are not at risk for cervical cancer, and may not be adequately informed about the need for screenings. We recommend strategies to disseminate recommendations and information to patients, their families, and care providers.

Key words: Unnecessary procedures, Papanicolaou test, Hysterectomy, United States

\section{INTRODUCTION}

Papanicolaou (Pap) tests are commonly used to detect precancerous lesions that can lead to cervical cancer. It has been reported that over 12500 women are annually diagnosed

Received: January 27, 2018 Accepted: June 1, 2018

Corresponding author: James R. Langabeer II, PhD

School of Biomedical Informatics, University of Texas Health Science

Center, 7000 Fannin Street Suite 600, Houston, TX 77030, USA

E-mail: James.R.Langabeer@uth.tmc.edu

This is an Open Access article distributed under the terms of the Creative Commons Attribution Non-Commercial License (http://creativecommons.org/licenses/by$\mathrm{nc} / 4.0 / /$ which permits unrestricted non-commercial use, distribution, and reproduction in any medium, provided the original work is properly cited. with cervical cancer in the US alone, with white women having an overall higher age-adjusted cancer incidence rate (50.1 per 100000 ) and ages 40-44 being the highest overall risk group (14.7 per 100 000) [1]. However, after a hysterectomy (i.e., removal of both the cervix and the uterus), the incidence of cervical cancer is extremely low $(0.42$ high-grade lesions per 1000 Pap tests), and hysterectomy-corrected cervical cancer mortality rates vary by age and race [2,3]. Therefore, screening with human papillomavirus testing alone or with cytology could be clinically harmful $[4,5]$. Repeated sampling poses risks of vaginal bleeding, pain, infection, and psychological distress such as anxiety or concern, discomfort, and sexual dysfunction [6]. Because of these risks, the US Preventive Ser- 
vices Task Force has recommended that women avoid screening if they have no history of high-grade dysplasia or prior history of cervical cancer after hysterectomy with removal of the cervix [6].

Nevertheless, according to a population-based study that analyzed data from the 2010 National Health Interview Survey, nearly $65 \%$ of all women aged $30+$ years with a history of hysterectomy reported receiving a Pap test within 3 years posthysterectomy [7], although this has apparently declined in recent years (from $73.3 \%$ in 2000 to $58.7 \%$ in 2010) [8]. Likewise, such unnecessary use is likely to exacerbate the current financial problems faced by the National Breast and Cervical Cancer Early Detection Program at the population level [9]. These financial problems affect all states, which are required to implement cost-effective preventive screening and treatment programs to provide free or low-cost services aimed at low-income, underserved, or underinsured/uninsured women for screening and diagnosis of cervical cancer. Discontinuing unnecessary cervical cancer screening for women without a cervix who evidently gain no benefits from such screening should receive special policy attention [10].

Prior studies have suggested that demographic and social determinants may influence rates of cervical cancer screening $[7,9,10]$. This research extends the literature with updated comprehensive evidence, applying a comprehensive weighting methodology known as raking. Our objective was to identify determinants of potentially unnecessary cervical cancer screenings.

\section{METHODS}

We identified determinants of potentially clinically unnecessary Pap tests after a hysterectomy based on the behavioral model of healthcare utilization as a conceptual framework [11]. This model suggests that socio-demographic, socioeconomic, health system, and individual factors influence patterns of healthcare use, and it is especially useful for explaining variations across social, racial, and ethnic groups. We hypothesized that these factors would be associated with patterns of cervical cancer screening. The independent variables selected for the analysis included age, race, ethnicity, marital status, education, family income, health insurance coverage, burden of medical costs (i.e., "needed to see a doctor but could not because of cost"), access to primary care physician $(\mathrm{PCP})$, health status, and time since the last routine checkup.
The outcome variable of our study was whether women with a history of hysterectomy received a Pap test within the last 3 years (binary) based on the 2014 Behavioral Risk Factor Surveillance System (BRFSS) core questions ("Have you had a hysterectomy?", "Have you ever had a Pap test?", and "How long has it been since you had your last Pap test?").

The BRFSS survey is a telephone survey conducted by the Centers for Disease Control and Prevention (CDC) that collects data from adult individuals about their reported healthcare utilization, behaviors, and risks across all 50 states, the District of Columbia, Puerto Rico, and Guam, targeting a representative sample of the population [12]. The BRFSS survey utilizes a complex survey design incorporating disproportionate, cluster, and stratified sampling techniques based on random-digit dialing of telephone numbers using computer-assisted telephone interviewing systems. The median response rate for all states was $47.0 \%$ (range, 25.1 to $60.1 \%$; landline response rate, $48.7 \%$; cell phone response rate, $40.5 \%$ ) [12]. For our study, we focused on adult women ( $>18$ years) and the subset of adult women who reported having received a Pap test within the last 3 years.

This population-based, retrospective, cross-sectional study relied on data from the 2014 BRFSS survey and employed several analytic strategies. We first calculated proportions and frequencies for categorical variables using unweighted and weighted estimates. The second strategy was to test associations between categorical outcomes and explanatory variables using the chi-square test. The last was to perform bivariate and multivariate logistic regression analyses to examine the strength of the relationship between each selected factor and whether a woman received a Pap test after a hysterectomy without and with controlling for confounders, respectively.

We calculated weighted estimates that included proportions and odds ratios (ORs) using a new weighting process (raking) for complex survey design that has been employed since 2011. This "raking" or iterative proportional fitting can more accurately match sample distributions underrepresented in the sample population to known population demographics, such as age, gender, race/ethnicity, geographic region, educational level, marital status, and homeownership status of respondents alone or together (e.g., age-, gender, or area-byrace/ethnicity). Raking also employs the dual-frame survey design to account for the overlapping sample frames ascribed to survey respondents who had both landline and cellular telephones. For the final weighting (i.e., to assign the rakingderived weight to each respondent), we used the raking vari- 
Table 1. Sample ${ }^{1}$ characteristics of adult women who had received a Papanicolaou (Pap) test in the last 3 years and had a prior hysterectomy, 2014 US Behavioral Risk Factor Surveillance System (BRFSS) survey²

\begin{tabular}{|c|c|c|c|c|c|c|c|}
\hline & \multicolumn{2}{|c|}{$\begin{array}{l}\text { Characteristics of women who } \\
\text { received both Pap test and } \\
\text { hysterectomy in last } 3 y\end{array}$} & \multicolumn{5}{|c|}{$\begin{array}{l}\text { Proportion of women with a prior hysterectomy who had } \\
\text { received a Pap test within the last } 3 \text { y }\end{array}$} \\
\hline & \multirow{2}{*}{ Unweighted } & \multirow{2}{*}{ Weighted } & \multirow{2}{*}{ Unweighted } & \multirow{2}{*}{ Weighted } & \multicolumn{2}{|c|}{$95 \% \mathrm{Cl}$} & \multirow{2}{*}{$p$-value ${ }^{3}$} \\
\hline & & & & & LL & UL & \\
\hline Total & & & 45.5 & 52.6 & 51.9 & 53.3 & \\
\hline $\begin{array}{c}\text { Age (y) } \\
18-44 \\
45-64 \\
\geq 65\end{array}$ & $\begin{array}{r}32935 \\
8.1 \\
48.7 \\
43.3\end{array}$ & $\begin{array}{r}12514996 \\
9.9 \\
45.3 \\
44.8\end{array}$ & $\begin{array}{l}72.4(2654) \\
56.5(16022) \\
35.3(14259)\end{array}$ & $\begin{array}{l}75.8 \text { (1 } 790922) \\
60.6(6524263) \\
39.4(4199812)\end{array}$ & $\begin{array}{l}73.2 \\
59.5 \\
38.5\end{array}$ & $\begin{array}{l}78.2 \\
61.7 \\
40.4\end{array}$ & $<0.001$ \\
\hline $\begin{array}{l}\text { Race/ethnicity } \\
\text { White, N-H } \\
\text { Black, N-H } \\
\text { Hispanic } \\
\text { Asian, N-H } \\
\text { Al/AN } \\
\text { Other }\end{array}$ & $\begin{array}{r}32492 \\
76.4 \\
12.6 \\
7.0 \\
0.7 \\
1.4 \\
2.0\end{array}$ & $\begin{array}{r}12332802 \\
74.5 \\
12.7 \\
8.8 \\
1.3 \\
1.1 \\
1.6\end{array}$ & $\begin{array}{l}42.3(24816) \\
63.7(4078) \\
64.7(2268) \\
57.3(225) \\
47.9(443) \\
44.0(662)\end{array}$ & $\begin{array}{l}48.0 \text { (8 } 391592) \\
67.9 \text { (2 } 024 \text { 896) } \\
68.3 \text { (1 } 404 \text { 119) } \\
60.4 \text { (183 406) } \\
53.7(137442) \\
49.5 \text { (191 351) }\end{array}$ & $\begin{array}{l}47.2 \\
65.8 \\
65.1 \\
47.3 \\
47.4 \\
44.0\end{array}$ & $\begin{array}{l}48.7 \\
70.0 \\
71.4 \\
72.2 \\
59.8 \\
55.0\end{array}$ & $<0.001$ \\
\hline $\begin{array}{l}\text { Marital status }^{5} \\
\text { Not married } \\
\text { Married }\end{array}$ & $\begin{array}{r}32778 \\
46.3 \\
53.7\end{array}$ & $\begin{array}{r}12467247 \\
46.9 \\
53.1\end{array}$ & $\begin{array}{l}40.7(15175) \\
50.7(17603)\end{array}$ & $\begin{array}{l}48.4(5372 \text { 127) } \\
56.4(7095122)\end{array}$ & $\begin{array}{l}47.4 \\
55.4\end{array}$ & $\begin{array}{l}49.4 \\
57.3\end{array}$ & $<0.001$ \\
\hline $\begin{array}{l}\text { Education } \\
<\text { High school } \\
1-3 \text { y of college } \\
\geq 4 \text { y of college }\end{array}$ & $\begin{array}{r}32853 \\
40.6 \\
30.1 \\
29.2\end{array}$ & $\begin{array}{r}12485535 \\
48.4 \\
33.0 \\
18.6\end{array}$ & $\begin{array}{l}43.3(13353) \\
44.7(9894) \\
50.1(9606)\end{array}$ & $\begin{array}{l}51.0(5850229) \\
52.3(4095117) \\
57.6(2540191)\end{array}$ & $\begin{array}{l}50.0 \\
51.0 \\
56.3\end{array}$ & $\begin{array}{l}52.1 \\
53.5 \\
58.9\end{array}$ & $<0.001$ \\
\hline $\begin{array}{l}\text { Family income ( } 10^{3} \text { US dollar) } \\
\quad<25 \\
\geq 25-<50 \\
\geq 50-<75 \\
\geq 75\end{array}$ & $\begin{array}{r}27603 \\
32.2 \\
27.4 \\
15.8 \\
24.5\end{array}$ & $\begin{array}{r}10592474 \\
36.5 \\
27.7 \\
14.1 \\
21.7\end{array}$ & $\begin{array}{l}40.8(8897) \\
43.4(7569) \\
51.0(4373) \\
57.0(6764)\end{array}$ & $\begin{array}{l}49.1 \text { (3 } 560575) \\
50.0(2755182) \\
56.0(1566896) \\
62.7(2709823)\end{array}$ & $\begin{array}{l}47.7 \\
48.5 \\
54.0 \\
61.0\end{array}$ & $\begin{array}{l}50.4 \\
51.4 \\
58.0 \\
64.3\end{array}$ & $<0.001$ \\
\hline $\begin{array}{l}\text { Health status }^{6} \\
\text { Not healthy } \\
\text { Healthy }\end{array}$ & $\begin{array}{r}32817 \\
24.9 \\
75.1\end{array}$ & $\begin{array}{r}12462975 \\
29.4 \\
70.6\end{array}$ & $\begin{array}{l}41.8(8159) \\
46.9(24658)\end{array}$ & $\begin{array}{l}48.8 \text { (3 } 395629) \\
54.3 \text { (9 } 067348)\end{array}$ & $\begin{array}{l}47.4 \\
53.4\end{array}$ & $\begin{array}{l}50.2 \\
55.1\end{array}$ & $<0.001$ \\
\hline $\begin{array}{l}\text { Medical cost burden } \\
\text { No } \\
\text { Yes }\end{array}$ & $\begin{array}{r}32861 \\
89.4 \\
10.6\end{array}$ & $\begin{array}{r}12453118 \\
86.8 \\
13.2\end{array}$ & $\begin{array}{l}45.3(29391) \\
47.3(3470)\end{array}$ & $\begin{array}{l}52.6(10808474) \\
52.6(1644646)\end{array}$ & $\begin{array}{l}50.5 \\
51.8\end{array}$ & $\begin{array}{l}54.8 \\
53.3\end{array}$ & 0.95 \\
\hline $\begin{array}{l}\text { Last routine checkup }(y)^{8} \\
\quad<1 \\
<2 \\
<5 \\
\geq 5\end{array}$ & $\begin{array}{r}32537 \\
87.7 \\
8.5 \\
2.5 \\
1.3\end{array}$ & $\begin{array}{r}12352705 \\
85.0 \\
8.4 \\
3.7 \\
3.0\end{array}$ & $\begin{array}{l}47.3(28542) \\
46.0(2766) \\
30.2(802) \\
20.1(427)\end{array}$ & $\begin{array}{l}54.4(10824319) \\
53.2(1042517) \\
36.3(315250) \\
24.7(170621)\end{array}$ & $\begin{array}{l}53.6 \\
50.8 \\
32.6 \\
21.3\end{array}$ & $\begin{array}{l}55.2 \\
55.7 \\
40.1 \\
28.4\end{array}$ & $<0.001$ \\
\hline $\begin{array}{l}\text { PCP9 } \\
\text { No } \\
\text { Yes }\end{array}$ & $\begin{array}{r}32861 \\
5.2 \\
94.8\end{array}$ & $\begin{array}{r}12470077 \\
6.8 \\
93.2\end{array}$ & $\begin{array}{l}42.3(1701) \\
45.7(31160)\end{array}$ & $\begin{array}{l}50.1 \text { (805 650) } \\
52.8 \text { (11 664 428) }\end{array}$ & $\begin{array}{l}46.8 \\
52.1\end{array}$ & $\begin{array}{l}53.3 \\
53.6\end{array}$ & 0.10 \\
\hline $\begin{array}{l}\text { Health coverage } \\
\text { No } \\
\text { Yes }\end{array}$ & $\begin{array}{r}32873 \\
3.8 \\
96.2\end{array}$ & $\begin{array}{r}12494848 \\
5.9 \\
94.1\end{array}$ & $\begin{array}{l}43.6(1261) \\
45.6(31612)\end{array}$ & $\begin{array}{l}47.3(659929) \\
53.0(11834920)\end{array}$ & $\begin{array}{l}44.0 \\
52.3\end{array}$ & $\begin{array}{l}50.6 \\
53.7\end{array}$ & 0.001 \\
\hline
\end{tabular}

Values are presented as number, $\%$ or $\%$ (number).

Cl, confidence interval; LL, lower limit; UL, upper limit; N-H, non-Hispanic; Al/AN, American Indian/Alaska Native; PCP, primary care physician.

'Differences in sample responses between groups reflect missing values due to incomplete or unreported vales in the survey response.

${ }^{2}$ The 2014 BRFSS data included all 50 states of the US, the District of Columbia, Guam, and Puerto Rico.

${ }^{3} p$-values were based on the chi-square test between 2 categorical variables (i.e., the outcome variable of whether women received a Pap test within 3 years [coded 1] or not [coded 0] versus other variables as risk factors).

"For the variable 'race/ethnicity,' Asian/non-Hispanic includes "Asian only, N-H.” Other includes "Native Hawaiian or other Pacific Islander only, N-H," "multiracial, $\mathrm{N}-\mathrm{H}$," and "other race only, N-H."

${ }^{5}$ For the variable "marriage," "not married” includes "divorced," "widowed," "separated," "never married," and "a member of an unmarried couple."

${ }^{6}$ For the variable "health status," "not healthy" indicates fair and poor health.

7The variable "medical cost burden" answers the question "Was there a time in the past 12 months when you needed to see a doctor but could not because of cost?" ${ }^{8}$ The variable "last routine checkup" answers the question "About how long has it been since you last visited a doctor for a routine checkup?"

9The variable "PCP" answers the question "Do you have one person you think of as your personal doctor or healthcare provider?"

${ }^{10}$ The variable "health coverage" answers the question "Do you have any kind of healthcare coverage, including health insurance, prepaid plans such as Health Maintenance Organizations, or government plans such as Medicare, or Indian Health Service?” 
able "_LLCPWT" to obtain final weighted estimates. We compared and validated all weighted estimates to those of the 2014 Codebook Report [12]. Statistical significance for all variables was determined at the $95 \%$ confidence interval (CI) level. We used Stata version 14.2 (StataCorp., College Station, TX, USA) for data management and statistical analyses.

Table 2. Bivariate and multivariate results for women with a prior hysterectomy and a Papanicolaou test within the last 3 years, 2014 US Behavioral Risk Factor Surveillance System

\begin{tabular}{|c|c|c|}
\hline & Bivariate & Multivariate \\
\hline $\begin{array}{c}\text { Age (y) } \\
18-44 \\
45-64 \\
\geq 65\end{array}$ & $\begin{array}{l}1.00 \text { (reference) } \\
0.49(0.43,0.57)^{* * *} \\
0.21(0.18,0.24)^{* * *}\end{array}$ & $\begin{array}{l}1.00 \text { (reference) } \\
0.43(0.36,0.50)^{* * *} \\
0.18(0.16,0.21)^{* * *}\end{array}$ \\
\hline $\begin{array}{l}\text { Race/ethnicity } \\
\text { White, N-H } \\
\text { Black, N-H } \\
\text { Hispanic } \\
\text { Asian, N-H } \\
\text { Al/AN } \\
\text { Other }\end{array}$ & $\begin{array}{l}1.00 \text { (reference) } \\
2.29(2.07,2.53)^{* * *} \\
2.34(2.02,2.71)^{* * *} \\
1.66(0.97,2.81) \\
1.26(0.98,1.61) \\
1.06(0.85,1.33)\end{array}$ & $\begin{array}{l}1.00 \text { (reference) } \\
2.23(1.99,2.50)^{* * *} \\
2.34(1.97,2.80)^{* * *} \\
1.16(0.68,1.96) \\
1.22(0.91,1.63) \\
1.12(0.87,1.44)\end{array}$ \\
\hline $\begin{array}{l}\text { Marital status } \\
\text { Not married } \\
\text { Married }\end{array}$ & $\begin{array}{l}1.00 \text { (reference) } \\
1.38(1.30,1.46)^{* * *}\end{array}$ & $\begin{array}{l}1.00 \text { (reference) } \\
1.17(1.08,1.27)^{* * *}\end{array}$ \\
\hline $\begin{array}{l}\text { Education } \\
<\text { High school } \\
1-3 \text { y of college } \\
\geq 4 \text { y of college }\end{array}$ & $\begin{array}{l}1.00 \text { (reference) } \\
1.05(0.98,1.12) \\
1.30(1.21,1.40)^{* * *}\end{array}$ & $\begin{array}{l}1.00 \text { (reference) } \\
0.93(0.85,1.01) \\
1.03(0.94,1.12)\end{array}$ \\
\hline $\begin{array}{l}\text { Family income }\left(10^{3} \text { US dollar) }\right. \\
\quad<25 \\
\quad \geq 25-<50 \\
\geq 50-<75 \\
\geq 75\end{array}$ & $\begin{array}{l}1.00 \text { (reference) } \\
1.04(0.96,1.12) \\
1.32(1.20,1.16)^{* * *} \\
1.74(1.59,1.90)^{* * *}\end{array}$ & $\begin{array}{l}1.00 \text { (reference) } \\
1.04(0.95,1.14) \\
1.15(1.02,1.30)^{*} \\
1.36(1.20,1.53)^{* * *}\end{array}$ \\
\hline $\begin{array}{l}\text { Health status } \\
\text { Not healthy } \\
\text { Healthy }\end{array}$ & $\begin{array}{l}1.00 \text { (reference) } \\
1.25(1.17,1.33)^{* * *}\end{array}$ & $\begin{array}{l}1.00 \text { (reference) }^{* * *}(1.14,1.35)^{* *}\end{array}$ \\
\hline $\begin{array}{l}\text { Medical cost burden } \\
\text { No } \\
\text { Yes }\end{array}$ & $\begin{array}{l}1.00 \text { (reference) } \\
1.00(0.92,1.10)\end{array}$ & $\begin{array}{l}1.00 \text { (reference) } \\
0.92(0.81,1.03)\end{array}$ \\
\hline $\begin{array}{l}\text { Last routine checkup (y) } \\
\quad<1 \\
\quad<2 \\
\quad<5 \\
\geq 5\end{array}$ & $\begin{array}{l}1.00 \text { (reference) } \\
0.96(0.86,1.06) \\
0.48(0.41,0.56)^{* * *} \\
0.27(0.23,0.33)^{* * *}\end{array}$ & $\begin{array}{l}1.00 \text { (reference) } \\
0.80(0.71,0.91)^{* * *} \\
0.39(0.32,0.48)^{* * *} \\
0.24(0.19,0.30)^{* * *}\end{array}$ \\
\hline $\begin{array}{l}\text { PCP } \\
\text { No } \\
\text { Yes }\end{array}$ & $\begin{array}{l}1.00 \text { (reference) } \\
1.12(0.98,1.28)\end{array}$ & $\begin{array}{l}1.00 \text { (reference) } \\
1.10(0.92,1.31)\end{array}$ \\
\hline $\begin{array}{l}\text { Health coverage } \\
\text { No } \\
\text { Yes }\end{array}$ & $\begin{array}{l}1.00 \text { (reference) }^{*} \\
1.26(1.10,1.44)^{*}\end{array}$ & $\begin{array}{l}1.00 \text { (reference) } \\
1.54(1.28,1.84)^{* * *}\end{array}$ \\
\hline
\end{tabular}

Values are presented as odds ratio (95\% confidence interval), weighted. $\mathrm{N}-\mathrm{H}$, non-Hispanic; Al/AN, American Indian/Alaska Native; PCP, primary care physician.

${ }^{*} p<0.05,{ }^{* *} p<0.001$.

\section{RESULTS}

A total of 32935 adult women ( $\geq 18$ years) reported having received a Pap test within the last 3 years and having a prior hysterectomy. Table 1 summarizes the study sample characteristics and between-group differences analyzed using the chi-square test.

The overall proportion of women with a prior hysterectomy who received a Pap test within the last 3 years was $52.6 \%$ (weighted). Significantly higher proportions were found among women aged $18-44(75.8 \% ; 95 \% \mathrm{Cl}, 73.2$ to $78.2 \%)$, black/non-Hispanic women $(67.9 \%, 95 \% \mathrm{Cl}, 65.8$ to $70.0 \%)$, Hispanic women $(68.3 \%, 95 \% \mathrm{Cl}, 65.1$ to $71.4 \%)$, those who were married $(56.4 \%, 95 \% \mathrm{Cl}, 55.4$ to $57.3 \%)$, those who had completed $\geq 4$ years of college $(57.6 \% ; 95 \% \mathrm{Cl}, 56.3$ to $58.9 \%)$, those with a family income $\geq \$ 75000(62.7 \% ; 95 \% \mathrm{Cl}, 61.0$ to $64.3 \%)$, those who were healthy $(54.3 \% ; 95 \% \mathrm{Cl}, 53.4$ to $55.1 \%)$, those with $<1$ year since their last routine checkup (54.4\%; $95 \% \mathrm{Cl}, 53.6$ to $55.2 \%$ ), and those who had health coverage ( $53.0 \%$; $95 \% \mathrm{Cl}, 52.3$ to $53.7 \%$ ).

The results of multivariate logistic regression are presented in Table 2. We found that age, race/ethnicity, marital status, family income, health status, time since last routine checkup, and health insurance coverage were all significant predictors. Education, cost burden, and having a PCP were not significant, although education was independently significant in the bivariate analysis (OR, 1.30; $95 \% \mathrm{Cl}, 1.21$ to 1.40 for those with $\geq 4$ years of college compared to those with a high school education or less). Older women were less likely to have received a Pap test and to have a prior hysterectomy. Compared to white, non-Hispanic women as the reference group, the OR for black, non-Hispanic women was $2.23(95 \% \mathrm{Cl}, 1.99$ to 2.50$)$ and the OR for Hispanic women was $2.34(95 \% \mathrm{Cl}, 1.97$ to 2.80). For married women, the relative odds of having received a Pap test and having a prior hysterectomy were 1.17 times higher than for unmarried women (OR, 1.17; $95 \% \mathrm{Cl}, 1.08$ to 1.27). The odds were 1.24 times higher for women who were healthier (OR, 1.24; $95 \% \mathrm{Cl}, 1.14$ to 1.35 ) and 1.54 times higher for women who had health insurance coverage $(\mathrm{OR}, 1.54 ; 95 \% \mathrm{Cl}, 1.28$ to 1.84$)$, after controlling for confounders.

\section{DISCUSSION}

We found that social and demographic determinants influenced whether women with prior hysterectomy received po- 
tentially unnecessary cervical cancer screenings. The findings regarding groups of women with a lower proportion of having received Pap tests within the last 3 years after hysterectomyin the categories of $\geq 65$ years of age, single, family income $<\$ 25000$, not healthy, with their last physical checkups $>5$ years ago, and no health insurance coverage-persisted in the multivariate analysis of determinants of potentially unnecessary Pap tests.

Age was a significant factor. Our findings suggest that younger women were far more likely to have obtained a potentially clinically unnecessary Pap test than older women. The higher utilization pattern for potentially unnecessary Pap tests may reflect their misunderstandings or misconceptions about Pap tests, pelvic exams, and other screening tests such as vaginal cancer screening [12]. It may also have been due to misconceptions about the need for a Pap test [13] or lack of awareness about cancer risk after total hysterectomy [14]. Finally, some patients may express an unwillingness to adhere to their PCP's decision about the screening interval [15].

Similar to other studies, minority women were twice as likely to obtain a potentially clinically unnecessary Pap test (i.e., Pap testing within the last 3 years, with a history of hysterectomy) than white/non-Hispanic women $[7,9,14]$. Although this use pattern is also present among women who have not undergone a hysterectomy, their cervical cancer mortality is much higher than that of white/non-Hispanic women [7]. The cervical cancer incidence and prevalence of human papillomavirus (causing cervical cancer) are higher in minority women than in white/non-Hispanic women [8]. While Pap tests are recommended for healthy minority women with a cervix, they could be potentially unnecessary for low-risk women who have had a hysterectomy $[4,15]$. To this end, there should be broader dissemination of the clinical recommendations via mass media, patient reminders, or through individual consultations to inform patients of the risks and benefits. Policymakers and community health advocates should focus more on race/ethnic populations that are likely to receive unnecessary cervical cancer screening.

In contrast to several prior studies, we found that education was not a significant factor in the multivariate model after controlling for other confounders. This could have been due to issues with the categories themselves, or with the sample itself. We found that women with $\geq 4$ years of college had a significantly higher potentially clinically unnecessary Pap test rate than women with a high school education or less by $30 \%(p<0.001)$.
We also found that that women with health insurance coverage, an overall healthy condition, and higher annual income were more likely to have had a Pap test and a history of hysterectomy. This is in line with previous studies $[7,9,16]$. It is unclear why women with a higher family income and better health status, education, and health insurance coverage tended to receive unnecessary cervical cancer screenings. Future studies are needed to investigate the causal relationships among these factors.

Our study also found that women who had their last routine checkup less than 2 years ago were more likely to have received a Pap test than those without a regular checkup in the last 5 years. This could partially be because women with a longer duration since their last routine checkup may make less of an effort to receive a Pap test, regardless of whether they have had a hysterectomy [14]. However, contrary to that study, we found that having a regular physician was not a significant factor. Our finding regarding the insignificant effect of having a PCP on unnecessary screenings may underscore the findings of other studies that many women did not adhere to their PCP's recommendations and tended to rely on their gynecologist $[16,17]$. Many physicians continued to recommend screenings despite these guidelines $[18,19]$.

Medical cost burden was not an enabling factor for receiving unnecessary Pap tests. This suggests that the decision to have a Pap test after hysterectomy is made regardless of socioeconomic vulnerability or the financial burden of healthcare costs. The reasons for this might partially include the implementation of the Affordable Care Act, which allowed women to receive proven preventive care (such as cervical cancer screening) at no additional cost. Alternatively, the personal preferences of individual patients for more comprehensive and frequent screening could partially explain these results [15].

This study had several limitations. First, Pap tests after a hysterectomy may have been over-reported simply due to self-reports by participants who could not accurately recall the difference between a Pap test and other similar screening tests $[13,17]$ and/or due to inaccuracies in self-reporting in national cross-sectional survey data, which may include overestimations of cancer screening utilization. However, the self-reported BRFSS data have been reported to be reliable and comprehensive relative to other data sources [20]. Sirovich and Welch [15] reported in JAMA that their analysis of BRFSS data between 1992 and 2002 showed that nearly half of all women with a prior hysterectomy were being screened unnecessarily [15]. 
Perhaps most importantly, the BRFSS survey data do not contain information about the actual dates of the Pap tests and hysterectomies during the last 3-year period. This makes it difficult to determine whether the individual had been screened right before or right after the hysterectomy. This is a limitation of the dataset itself, given the wording of the question. Furthermore, some populations that lack either home or cell phones could have been under-represented, which may limit the generalizability of the findings.

In summary, this study found that certain social and racial demographic groups had greater relative odds for receiving potentially unnecessary Pap tests. We found that $45 \%$ of the study participants (or 32935 women) might have undergone unnecessary testing, defined as Pap testing within the last 3 years combined with a prior hysterectomy. Using CDC population adjustments, this could equate to 12.5 million such women across the US. Future studies should examine better ways to assess unnecessary use, considering the timing of the hysterectomy. Even more importantly, future research should explore the generalizability of these findings and prevalence rates across other countries and regions, including Europe and Asia [21].

Based on our findings from this population-based dataset, many women may undergo potentially clinically unnecessary cervical testing. Our study provides evidence about which racial and social demographic groups are most likely to receive unnecessary testing, so that targeted awareness and information campaigns can be developed for these specific populations. Understanding these demographic differences should be useful to policymakers, care providers, and others to reduce the frequency of potentially clinically unnecessary Pap tests.

\section{ACKNOWLEDGEMENTS}

The authors appreciate the assistance of David Ruiz, Dr. Monique Sheppard, Tom Jackson, Dr. Ying Li, Meredith Chen, Jonathan Fusfield, and Cahdi Jones.

\section{CONFLICT OF INTEREST}

The authors have no conflicts of interest associated with the material presented in this paper.

\section{ORCID}

James R. Langabeer II http://orcid.org/0000-0002-2304-4853

\section{REFERENCES}

1. Centers for Disease Control and Prevention. United States Cancer Statistics (USCS): 1999-2014 incidence and mortality web-based report [cited 2018 Feb 12]. Available from: https:// www. cdc.gov/cancer/npcr/uscs/index.htm.

2. Rositch AF, Nowak RG, Gravitt PE. Increased age and race-specific incidence of cervical cancer after correction for hysterectomy prevalence in the United States from 2000 to 2009. Cancer 2014;120(13):2032-2038.

3. Beavis AL, Gravitt PE, Rositch AF. Hysterectomy-corrected cervical cancer mortality rates reveal a larger racial disparity in the United States. Cancer 2017;123(6):1044-1050.

4. US Preventive Services Task Force, Bibbins-Domingo K, Grossman DC, Curry SJ, Barry MJ, Davidson KW, et al. Screening for gynecologic conditions with pelvic examination: US Preventive Services Task Force recommendation statement. JAMA 2017;317(9):947-953.

5. Guirguis-Blake JM, Henderson JT, Perdue LA, Whitlock EP. Screening for gynecologic conditions with pelvic examination: a systematic review for the U.S. Preventive Services Task Force; 2017 [cited 2018 Jul 7]. Available from: https://www. ncbi.nlm.nih.gov/books/NBK442154/.

6. Moyer VA; U.S. Preventive Services Task Force. Screening for cervical cancer: U.S. Preventive Services Task Force recommendation statement. Ann Intern Med 2012;156(12):880-891.

7. Kepka D, Breen N, King JB, Meissner HI, Roland KB, Benard VB, et al. Demographic factors associated with overuse of Pap testing. Am J Prev Med 2014;47(5):629-633.

8. Centers for Disease Control and Prevention (CDC). Cervical cancer screening among women by hysterectomy status and among women aged $\geq 65$ years - United States, 2000-2010. MMWR Morb Mortal Wkly Rep 2013;61(51-52):1043-1047.

9. Saraiya M, Lee NC, Blackman D, Smith MJ, Morrow B, McKenna MA. Self-reported Papanicolaou smears and hysterectomies among women in the United States. Obstet Gynecol 2001; 98(2):269-278.

10. Centers for Disease Control and Prevention. National Breast and Cervical Cancer Early Detection Program (NBCCEDP): social ecological model [cited 2017 Oct 23]. Available from: https:// www.cdc.gov/cancer/nbccedp/sem.htm.

11. Andersen R, Aday LA. Access to medical care in the U.S.: realized and potential. Med Care 1978;16(7):533-546.

12. Centers for Disease Control and Prevention. Behavioral Risk Factor Surveillance System (BRFSS): 2014 BRFSS survey data 
and documentation [cited 2017 Oct 23]. Available from: https:// www.cdc.gov/brfss/annual_data/annual_2014.html.

13. Hawkins NA, Cooper CP, Saraiya M, Gelb CA, Polonec L. Why the Pap test? Awareness and use of the Pap test among women in the United States. J Womens Health (Larchmt) 2011;20(4): 511-515.

14. Hewitt M, Devesa SS, Breen N. Cervical cancer screening among U.S. women: analyses of the 2000 National Health Interview Survey. Prev Med 2004;39(2):270-278.

15. Sirovich BE, Welch HG. Cervical cancer screening among women without a cervix. JAMA 2004;291(24):2990-2993.

16. Meissner HI, Tiro JA, Yabroff KR, Haggstrom DA, Coughlin SS. Too much of a good thing? Physician practices and patient willingness for less frequent pap test screening intervals. Med Care 2010;48(3):249-259.

17. Crawford A, Benard V, King J, Thomas CC. Understanding barriers to cervical cancer screening in women with access to care,
Behavioral Risk Factor Surveillance System, 2014. Prev Chronic Dis 2016;13:E154.

18. Corbelli J, Borrero S, Bonnema R, McNamara M, Kraemer K, Rubio $D$, et al. Differences among primary care physicians' adherence to 2009 ACOG guidelines for cervical cancer screening. J Womens Health (Larchmt) 2014;23(5):397-403.

19. Cooper CP, Saraiya M. Opting out of cervical cancer screening: physicians who do not perform pap tests. Am J Prev Med 2014; 47(3):315-319.

20. Nelson DE, Powell-Griner E, Town M, Kovar MG. A comparison of national estimates from the National Health Interview Survey and the Behavioral Risk Factor Surveillance System. Am J Public Health 2003;93(8):1335-1341.

21. Anttila A, Ronco G, Clifford G, Bray F, Hakama M, Arbyn M, et al. Cervical cancer screening programmes and policies in 18 European countries. Br J Cancer 2004;91(5):935-941. 